\title{
Via Verde: nova expressão de centralidade em Rio Branco, Acre-Brasil
}

\author{
Via Verde: new expression of centrality in Rio Branco, Acre-Brazil
}

Janete Farias Mendonça[a,b] (1), Maria Madalena de Aguiar Cavalcante[c,d,e], Maria de Jesus Morais[f,g,h]

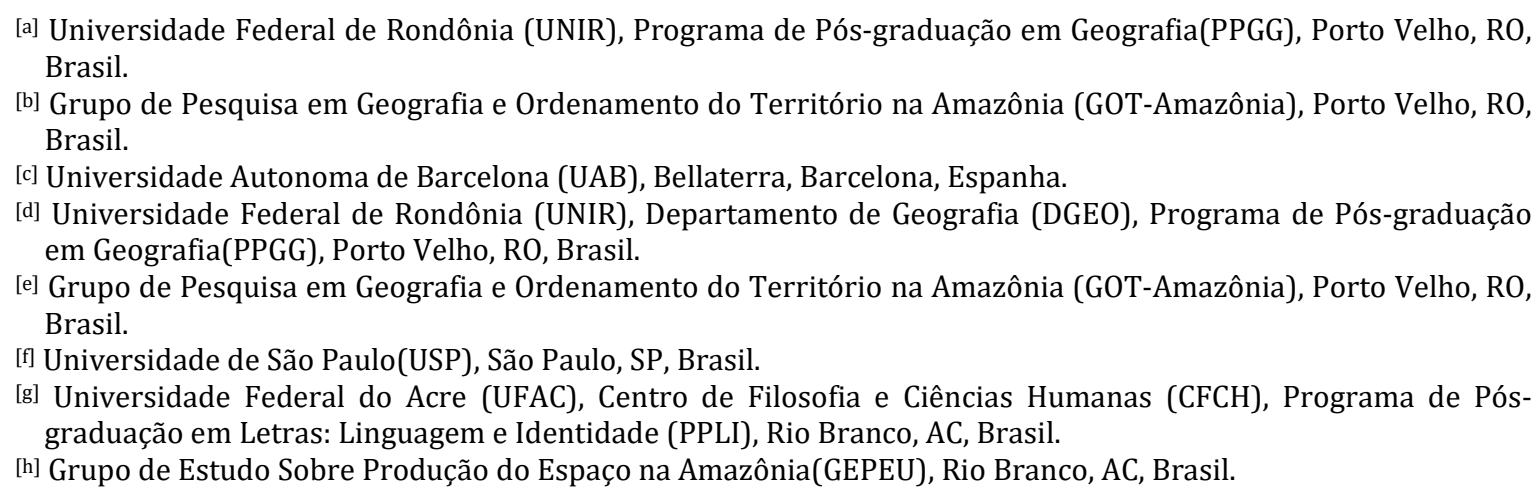

Como citar: Mendonça, J. F., Cavalcante, M. M. A., \& Morais, M. J. (2019). Via Verde: nova expressão de centralidade em Rio Branco, Acre-Brasil. urbe. Revista Brasileira de Gestão Urbana, 11, e20180129. https://doi.org/10.1590/21753369.011.e20180129

\section{Resumo}

O presente texto traz uma discussão acerca da valorização imobiliária em Rio Branco, capital do Estado do Acre. 0 poder público, como forma de direcionar o crescimento urbano para outra porção da cidade, decidiu criar um novo centro administrativo e descentralizar alguns serviços. A área destinada a receber esses serviços foi a Via Verde, um lugar com grandes extensões de "espaços vazios" que, aos poucos, foi sendo ocupado. Essa Via é parte da BR-364, que foi pavimentada em 2006 e, a partir da materialização de investimentos públicos e privados, ano após ano, tornou-se a área mais valorizada da cidade. Esse processo promove um mercado imobiliário formal restrito, que limita o acesso de grande parte da população aos espaços urbanos mais valorizados. No entanto, a descentralização desses serviços para essa alça viária é a materialização do desenvolvimento econômico na capital, pois tem incentivado novas rotas para a expansão territorial, além da inserção de atividades outrora alheias a essa cidade. Nesse sentido, o objetivo deste texto é discutir a materialização de investimentos na Via Verde e a valorização imobiliária que esses empreendimentos têm gerado no entorno dessa nova alça viária, tornando a uma nova expressão de centralidade em Rio Branco.

Palavras-chave: Rio Branco. Via Verde. Descentralização. Valorização imobiliária.

JFM é mestra em Geografia, membro do Grupo de Pesquisa em Geografia e Ordenamento do Território na Amazônia, e-mail: janetefarias12@gmail.com

MMAC é pós-doutora em Geografia, professora doutora, líder do Grupo de Pesquisa em Geografia e Ordenamento do Território na Amazônia, e-mail: mada.geoplan@gmail.com

MJM é pós-doutora em Geografia, professora doutora, líder do Grupo de Estudo Sobre Produção do Espaço na Amazônia, e-mail: mjmorais@hotmail.com 


\section{Abstract}

This text presents a discussion about real estate valuation in Rio Branco, capital of the state of Acre. The public power as a way to direct urban growth to another part of the city decides to create a new administrative center and decentralize some services. The area destined to receive these services is Via Verde. At first, it was a place with great extensions of "empty spaces" that gradually was being occupied. This highway is part of the BR-364 that was paved in 2006 and, from the materialization of public and private investments, year after year, it has become the most valued area of the city. This process promotes a restricted formal real estate market, which limits the access of a large part of the population to the most valued urban spaces. However, the decentralization of these services to this roadway is the materialization of economic development in the capital, as it has encouraged new routes for territorial expansion and insertion of activities formerly unrelated to this city. In this sense, the objective of this text is to discuss the materialization of investments in Via Verde and the real estate valuation that these ventures have generated around this new roadway, making it a new expression of centrality in Rio Branco.

Keywords: Rio Branco. Via Verde. Decentralization. Real estate valuation.

\section{Introdução}

É intrínseca a toda cidade a ocorrência de vários processos de natureza socioespacial responsáveis por (re)produzir o espaço urbano, os quais, além de dinamizarem o espaço, possibilitam novas configurações espaciais, pois criam formas e funções, isto é, atividades e suas materializações. Essas novas espacializações constituem-se na própria produção da cidade e, em certos casos, fazem parte do processo de descentralização e (re)centralização urbana.

A ocorrência desses processos, por sua vez, reforça a fragmentação do espaço urbano que passa a ser transformado, destruído e reconstruído ao longo do tempo e permite o surgimento de novas expressões de centralidade, geralmente, em áreas mais afastadas do centro principal, mas tais atividades, ao se estabelecerem e se intensificarem, geram novas dinâmicas tanto de fluxo (pessoas, mercadorias e capital) quanto dos componentes espaciais fixos.

A cidade apresenta-se como o lugar da divisão econômica, social e espacial, o lugar de concentração do capital e sua materialização, isto é, "[...] equipamentos, atividades e serviços de modo que as relações econômicas e sociais possam conquistar maior dinamicidade [...]" (Silva, 2003, p. 23). Nesse sentido, a cidade passa a ser (re)produzida sob novas lógicas capitalistas, gerando novas dinâmicas, e a inserir-se em um novo processo de (re)produção e acumulação do capital.

Essa nova (re)produção do capital, por si só, não se realizaria, caso não fosse impulsionada e/ou incentivada pelos grandes capitalistas, isto é, pelos principais agentes produtores e consumidores do espaço urbano, quais sejam: os proprietários do meio de produção, os proprietários fundiários, os promotores imobiliários, o Estado e os grupos sociais excluídos. A partir da ação desses agentes, que é repleta de interesses e contradições, o espaço é produzido e impregnado de materialidades como estradas, centros urbanos com ruas, bairros, áreas comerciais e fabris, etc. (Corrêa, 2012).

Rio Branco, capital do Estado do Acre, tem passado nos últimos anos por muitas mudanças, principalmente no que diz respeito à produção capitalista do espaço e às mudanças na dinâmica populacional, (no que tange ao aumento da população) bem como por transformações nas condições sociais e econômicas, dando a essa cidade um papel cada vez mais importante no contexto regional. Nos últimos anos, o governo e os empresários locais e nacionais têm "injetado" mais recursos na cidade; essa materialização de investimentos tem aquecido a economia local, tais como a construção do primeiro shopping da cidade, o Via Verde Shopping, a vinda dos hipermercados Makro e Atacadão, da rede de departamentos Havan e outros.

A materialização de investimentos em Rio Branco tem acontecido concomitante ao processo de descentralização e (re)centralização de alguns serviços públicos do centro da cidade para a Via Verde. Essa Via é parte da BR-364, que foi revitalizada para tornar uma área de comércio e serviços públicos e 
privados amplos e modernos, ou seja, uma nova centralidade. 0 processo de descentralização na cidade de Rio Branco vem acontecendo de maneira lenta, quando comparado a outras cidades médias de regiões econômicas mais dinâmicas no país. No entanto, não deixa de ser um processo relevante na produção do espaço urbano, na medida em que essas transformações têm levado a cidade a um novo processo de organização e estruturação das atividades.

Com esta publicação, objetiva-se discutir de que maneira ocorre a produção do espaço urbano na cidade de Rio Branco, tomando como ponto de partida o processo de descentralização e, (re)centralização das atividades de comércio e serviços e, a consequente valorização imobiliária no entorno da Via Verde entre 2004 e 2018.

Do ponto de vista metodológico, trilharam-se os seguintes passos: levantamento bibliográfico referente aos processos e às formas espaciais atuais em cidades médias; mapeamento na mídia local da instalação de novos empreendimentos; pesquisa sobre valor de terrenos na Via Verde em jornais impressos e on-line; entrevistas; e dados obtidos na Prefeitura de Rio Branco.

Em termos de estrutura, o texto encontra-se dividido em três partes, além desta introdução. $\mathrm{Na}$ primeira parte, será apresentada uma reflexão acerca das novas expressões de centralidade em cidades médias. Posteriormente, refletir-se-á sobre a materialização de investimentos na Via Verde. Por fim, o debate centrará na discussão da valorização imobiliária no entorno da Via Verde.

\section{Novas expressões de centralidade em cidades médias}

As cidades são transformadas a partir da (re)produção e da acumulação de capital de forma diferenciada; assim, com o tempo tanto as cidades, quanto o território são (re)estruturados, modificando as formas e atribuindo novos usos e ocupações às áreas. De acordo com Oliveira Júnior (2010, p. 88), "essas modificações caracterizam-se por uma tendência à desconcentração de investimentos na rede urbana com novas estratégias locacionais do capital, direcionadas aos territórios não-metropolitanos". Em outras palavras, ocorre uma movimentação econômico-territorial que tem diversificado a lógica locacional do capital, nos mais variados ramos das atividades produtivas, das metrópoles para as cidades médias.

Considera-se oportuno esclarecer que a definição do conceito de cidade média é complexa, uma vez que o contingente populacional não é determinante para caracterizar uma cidade como média. Cidade média é aquela que desempenha múltiplos papéis na rede urbana. Em outras palavras, é uma cidade intermediária, pois exerce uma função de mediação entre bens, informações, capital, inovações, administração etc (Silva, 2013).

De acordo com Sposito (2006), a leitura e a análise de uma cidade média devem estar articuladas em diferentes escalas de análise. Em outras palavras, é preciso relacionar fatores, como densidade demográfica, funções e usos urbanos que colocam a cidade média em diferentes papéis e situações na rede urbana. Essas articulações a diferenciam das demais cidades, uma vez que estas desempenham a função de intermediação no âmbito interurbano e intraurbano.

Por meio dessa intermediação econômico-territorial em âmbito interurbano é que os novos equipamentos se materializam na rede urbana, e é nesse momento que o espaço urbano passa a ser (re)organizado. Essa (re)organização, por sua vez, não acontece por acaso, mas a partir de determinações (políticas, econômicas e sociais) e conflitos de interesse.

Essas mudanças são perceptíveis em vários setores intraurbanos e fazem com que o espaço urbano ganhe complexidade, pois, à medida que ocorre um crescimento espacialmente descentralizado, há também uma (re)centralização das atividades em outro setor. Desse modo, o processo de descentralização relaciona-se com os movimentos e as tendências, além de estar associado à junção de vários fatores, como as deseconomias de aglomeração da área central e ao crescimento demográfico e espacial da cidade, a qual, por sua vez, insere-se no processo de acumulação de capital. 
Os novos equipamentos urbanos, por exemplo, os shopping centers, são considerados símbolos de desenvolvimento na escala intraurbana das cidades médias. Esses tipos de empreendimento, além de representarem a modernidade, surgem para vincular interesses entre grandes grupos de investidores e elites locais, e, geralmente, são construídos em áreas descentralizadas, distantes da área central.

0 processo de descentralização é bastante amplo, e seu significado não se conforma apenas à dispersão das atividades de comércio e serviços para áreas mais longínquas, mas também à criação de novas expressões de centralidade. Sposito (2001) destaca algumas das principais transformações que ocorrerem no processo de descentralização e (re)centralização: interesses dos imobiliários; crescimento demográfico; ampliação da diferenciação socioespacial; melhoria nos transportes públicos e individual etc. Já Corrêa (1989) aponta outro fatores, como aumento do preço da terra, impostos, aluguéis, etc, ou seja, processos sociais que fragmentam o espaço urbano.

Nesse sentido, o processo de descentralização, tem se destinado a cumprir funções específicas que variam segundo as necessidades das organizações sociais responsáveis por (re)produzir o espaço urbano, fato que gera uma verdadeira fragmentação espacial. Desse modo, o espaço urbano vira "[...] a condição essencial à realização de qualquer atividade produtiva e humana, tornando-se fonte de poder e dominação para quem o detém" (Bessa, et al., 1996, p. 164).

Ribeiro (2004) destaca os estudos de Proudfoot ao abordar as transformações ocorridas na estrutura comercial das cidades norte-americanas. Essas cidades, por serem mais populosas e em amplo processo de desenvolvimento, foram as primeiras a apresentar "sinais" ao processo de descentralização e (re)centralização das atividades terciárias. Por meio dessas análises, o autor classificou e caracterizou as atividades varejistas, criando uma tipologia quanto à localização e à distribuição dessas atividades no espaço urbano, fato que contribuiu, e contribui até hoje, para a identificação e a compreensão do processo de descentralização das estruturas comerciais das cidades.

Foi por intermédio da consolidação do processo de descentralização que o núcleo central passou a lidar com constantes transformações em razão do desdobramento das atividades para as áreas mais distantes. Esse processo, entretanto, não faz com que o centro perca sua função, mas contribui diretamente para uma redefinição funcional, no sentido de que o núcleo central deixa de monopolizar as atividades outrora conexas como indústrias, comércio e serviços, e passa a dividi-las com as (novas) centralidades. Essas novas centralidades são acompanhadas por processos de descentralização e (re)centralização, os quais movimentam fixos e fluxos e atribuem novas dinâmicas de uso ao espaço urbano.

À medida que a cidade cresce, tem-se a imposição de (novos) tempos e atores hegemônicos, e o processo de descentralização é um exemplo claro dessas realizações, pois o espaço urbano, ao ser fragmentado para a instalação de mais atividades, além de dinamizar um "novo espaço" na cidade, com formas e funções diferenciadas, suscita as novas expressões de centralidade. Nesses espaços até então "vazios", são implantadas atividades comerciais e de serviços, geralmente de grande porte, que já "surgem" territorialmente descentralizadas capazes de gerar e manter fluxos que, ao se estabelecerem e se intensificarem, materializam a criação de uma nova expressão de centralidade, o que redefine a própria noção de centralidade no espaço urbano.

Atualmente, nos grandes centros urbanos as conformações socioespaciais são bastante comuns, fato que gera novos padrões de centralidade ou centralidade poli(multi)cêntrica. 0 termo "poli(multi)cêntrica" é usado para caracterizar a capacidade de reprodução do capital em espaços diferenciados, em que "policêntrica" é usada como diferenciação social e funcional das áreas descentralizadas, e "multicêntrica", para caracterizar as várias centralidades. Essa centralidade foi sentida a priori nas grandes metrópoles por apresentar as melhores condições para a reprodução capitalista e, posteriormente, esse processo foi sentido nas cidades médias, inclusive nas cidades do Brasil a partir da década de 1990 (Silva, 2008).

A centralidade poli(multi)cêntrica é um processo amplo e ao mesmo tempo complexo. Essa complexidade advém porque todo espaço urbano evoca e provoca a concentração e a dispersão de atividades, capital etc. Desse modo, o espaço urbano demonstra que sempre tem estado, e sempre estará, concentrado e poli(multi)cêntrico. A ideia de uma centralidade única com subcentros de 
limitada expressão verificada nas cidades até a década de 1970 não faz parte há muito tempo da maioria das grandes e médias cidades brasileiras, por causa da existência dos vários eixos de desdobramentos (vias de fácil circulação, hipermercados, shopping centers) capazes de induzir as atividades para fora do centro principal.

Essa dinâmica já é sentida em vários centros urbanos, e o Estado de São Paulo é um exemplo bastante visível dessa "tendência", haja vista a diversidade de centros (financeiro, lazer e comercial) encontrados não apenas na área metropolitana, mas também no interior da cidade. Assim, tanto o aumento quanto a diversificação das áreas centrais permitem constatar a ocorrência de uma centralidade múltipla.

As cidades tendem a diversificar seus papéis impondo novas dinâmicas para o espaço, isto é, criam novos espaços de consumo no interior das cidades, cuja densidade seja expressiva o bastante para gerar e manter a dinamização entre os fixos e os fluxos. Para Montessoro (1999, p. 215), "[...] esse processo contribui para a própria valorização e (re)utilização de novas áreas [...]", o que traz a ideia de constante (re)criação, isto é, movimentos contínuos de construção/destruição/reconstrução de determinada porção da cidade que dá lugar a outros, dependendo do interesse dos capitalistas.

Assim, esses antigos espaços de consumo, aos poucos, vão deixando de ser os únicos propiciadores de maior circulação entre os fluxos e os fixos, dando lugar a novas centralidades, e os shopping centers e os hipermercados são exemplos de ocorrência das novas expressões de centralidades, pois são capazes de manter fortes vínculos interurbanos e intraurbanos, além de serem considerados ícones e signos da modernização e do desenvolvimento contemporâneo em cidades médias em territórios não-metropolitanos.

Segundo Sposito (2001), no Brasil, as novas formas comerciais (hipermercados, shopping centers, galerias etc.) surgiram a partir das décadas de 1980 e 1990, quando o processo de concentração econômica, isto é, concentração de interesses de grandes grupos do setor comercial e de serviços, impulsionados pelo capital internacional, intensificou-se. As novas formas de comércio diversificam tanto a centralidade intra-urbana, ao se articular com a nova expressão de centralidade, quebra a ideia de centralidade única verificada nas cidades até algumas décadas quanto a centralidade interurbana, visto que promove novos fluxos e articulação entre cidades de diferentes portes.

Ainda segundo Sposito (2001), a concentração econômica, entre vários outros fatores, é condicionante da rapidez e da qualidade da informação, uma vez que permite o ajuste constante da oferta e da demanda. Para a autora, a busca por informação também faz parte das novas lógicas territoriais que os agentes de produção imobiliários e os proprietários fundiários, principalmente, tiveram que buscar e/ou inovar para desenvolver suas atividades comercias de serviços com êxito.

Desde modo, compreende-se que os shopping center, reforçam o papel regional das cidades onde se instalam, pois propiciam novas formas de lazer e consumo, principalmente por meio das lojas de franquias das grifes restritas à metrópole. 0 advento do shopping center nas grandes e médias cidades tem contribuído de forma significativa para a transformação e a (re)estruturação espacial das atividades, uma vez que passou a ser a nova forma de (re)organizar as atividades de comércio e serviços nas áreas descentralizadas.

Tais apontamentos revelam a ideia de que o processo de (re)estruturação urbana pode ser avaliado de acordo com a disseminação e a construção dos shopping centers, visto que estes, ao serem instalados, mesmo sendo em áreas poucos movimentadas, produzem novas dinâmicas no espaço. Assim, a instalação dos shopping centers assume várias finalidades, como: (1) a multiplicação da centralidade na cidade; (2) a reafirmação dessa centralidade; (3) o direcionamento do crescimento urbano; (4) a promoção de reflexos de valorização do solo e dos imóveis vizinhos; (5) a possibilidade de uma organização estrutural das atividades terciárias, o que suscita as novas expressões de centralidades.

Essas centralidades sugerem também um processo de (re)valorização do espaço urbano, na medida em que a atração exercida por essas áreas implica alterações no preço e no acesso à terra urbana, principalmente no entorno imediato a essas novas centralidades, haja vista que os empreendimentos, ao serem instalados em áreas embora distantes da área central, trazem valorização para o solo e para os equipamentos implantados no entorno. 
A partir dessas transformações, tanto o centro tradicional como a nova área central passam a expressar centralidade, porém o centro tradicional tende a buscar novas alternativas para manter sua dinamização, para, então, competir com a nova centralidade. Nesse sentido, a imposição e/ou a disseminação dos novos equipamentos no espaço urbano possibilitam a conformação do processo de (re)estruturação de novos espaços urbanos, provocando a modificação da área central. Esta, de acordo com Oliveira (2010, p. 95),

[...] se redefine e reage para internalizar as externalidades da nova expressão de centralidade e suprir as novas demandas de mercado, objetivando concorrer com o Shopping Center ou direcionar suas atividades a outros segmentos sociais (Oliveira, 2010, p. 95).

Nesse sentido, a descentralização de determinadas atividades não é suficiente para a criação de novas expressões de centralidade, pois estas se criam essencialmente em decorrência dos fluxos que as atividades descentralizadas geram, portanto, fixos sem fluxos, não geram centralidade. Assim, são essas novas centralidades que gerenciam uma nova economia de mercado capaz de "modificar" o fluxo do núcleo central.

Dessa forma, as novas expressões de centralidade estão inseridas na tendência à desconcentração de investimentos na rede urbana com novas estratégias locacionais do capital e os shoppings centers e os hipermercados são exemplos claros dessa desconcentração e materialização de investimentos, geralmente, em áreas longínquas, mas que, ao se intensificarem, mudam completamente a dinâmica da cidade e, acima de tudo, geram novas centralidades.

\section{Via Verde: nova expressão de centralidade em Rio Branco}

A cidade de Rio Branco, capital do Estado do Acre, localiza-se na Amazônia Sul-Ocidental e, possui 336.038 habitantes, de acordo com o último censo populacional do Instituto Brasileiro de Geografia e Estatística (IBGE). Rio Branco tem passado nos últimos anos por muitas mudanças, principalmente no que diz respeito à dinâmica populacional (no que tange ao aumento da população), como também por transformações nas condições sociais e econômicas, dando a essa cidade um papel cada vez mais importante no contexto regional.

O crescimento demográfico e espacial gera mudanças significativas nas cidades e, a área central por oferecer todos os tipos de serviço, é a primeira a ser totalmente ocupada. Na cidade de Rio Branco, essa realidade não foi diferente. A movimentação socioespacial, associada à dinamização entre os fluxos, os fixos e o capital, suscitou a funcionalidade de praticamente todos os "espaços vazios" que restavam na área central.

Assim, nessa área, não há mais lugar para grandes edificações e sua consequente demanda, por exemplo, espaço para grandes estacionamentos e vias amplas que facilitem a mobilidade urbana. Outros fatores também contribuíram para o poder público tomar medidas de descentralizar alguns serviços da área central, como a necessidade de ampliação das estruturas de alguns órgãos públicos e a oportunidade de adquirir um prédio próprio, já que alguns prédios eram alugados e com estrutura antiga.

Desse modo, o poder público decidiu descentralizar algumas atividades administrativas e seguir a tendência dos modernos centros urbanos em concentrar, espacialmente, as atividades comerciais e os serviços públicos para melhor ocupação do solo e organização da cidade e, principalmente, promover o crescimento e a especulação imobiliária em outra parte da cidade neste caso, a Via Verde.

A Via Verde é um anel viário, parte da BR-364, que foi revitalizada em 2006. Essa alça viária Via Verde/BR-364 é a materialização do desenvolvimento econômico em Rio Branco, uma vez que incentivou novas rotas para a expansão territorial, além da inserção de atividades outrora alheias a essa cidade. Além disso, a Via Verde promoveu o deslocamento do fluxo da área central, sobretudo dos veículos de grande carga, que perpassavam diuturnamente pela área central.

A conclusão dessa alça viária e a abertura da Terceira Ponte favoreceu o escoamento dos fluxos intra-urbanos e interurbanos e possibilitaram mudanças na mobilidade urbana e transformação 
espacial de Rio Branco, pois acelerou o desenvolvimento da cidade na direção oeste e, consequentemente, ocasionou impactos sociais e econômicos.

Os primeiros órgãos a ser implantados na Via Verde datam de 2004, tais como Tribunal Regional Eleitoral, Justiça Federal, e Hospital das Clínicas. Nos anos posteriores, mais precisamente a partir de 2010, esse processo de descentralização se intensificou (Figura 1), e outros órgãos da Administração Pública foram construídos nessa área, bem como empreendimentos privados.

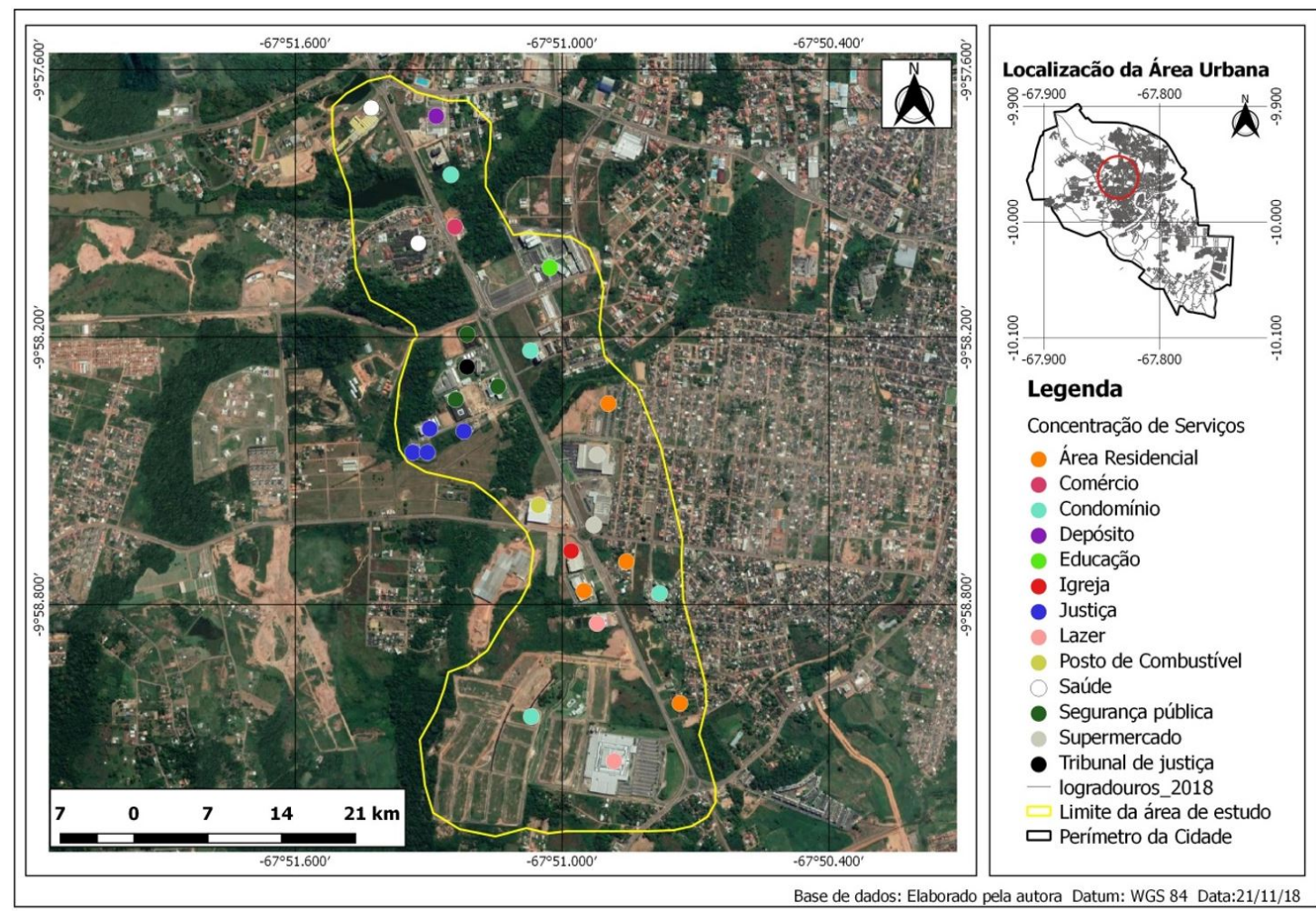

Figura 1 - Órgãos públicos e empreendimentos privados na Via Verde. Fonte: Base: Prefeitura de Rio Branco. Mosaico de imagens aéreas 2010. Datum: WGS 84. Elaborado por: Janete Farias. Data 10/10/2018.

A descentralização de órgãos públicos para fora das áreas centrais de cidades e metrópoles brasileiras e a formação de centros administrativos planejados impulsionam a valorização fundiária e imobiliária de áreas outrora pouco ocupadas. Os investimentos materializados na Via Verde, tanto da esfera pública quanto da privada, tais como a construção de equipamentos educacionais, administrativos, de saúde e de segurança, favoreceram uma rápida valorização imobiliária e mudanças nos usos do solo com o parcelamento fundiário para construção de loteamentos fechados no entono dessa área.

Nesse sentido, a produção do espaço urbano realizada pelo capital privado na Via Verde teve início em 2011, a partir da construção do primeiro shopping da cidade, o Via Verde Shopping (A Gazeta do Acre, 2011). Sua construção foi sem dúvida um dos maiores empreendimentos privados do Estado. Os shopping centers são apontados pela Associação Brasileira de Shoppings Centers (ABRASCE) como um marco de desenvolvimento para a região em que são instalados, pois o status de modernidade que eles apresentam garante a valorização das áreas de seu entorno. (Correio 24horas, 2012). Rio Branco assimilou "a demanda pelo empreendimento [vinda do primeiro shopping] e o perfil do consumidor", o que permitiu "o aumento médio do poder aquisitivo do acreano" (A Gazeta do Acre. Entrevista realizada em 06 de novembro de 2011).

A valorização imobiliária que os shoppings proporcionam acontece em todas as regiões do Brasil. Um exemplo é o Shopping Iguatemi em Salvador, que puxou o crescimento da cidade. Portanto, os shopping centers são uma vizinhança que agrega muito valor ao imóvel, tanto que, no entorno do 
Shopping Bela Vista em Salvador, essa valorização chegou a 90\%. Segundo a ABRASCE, a valorização imobiliária na região do entorno de um Shopping Center é de $46 \%$ superior ao restante da cidade. Entre os fatores que contribuem para essa valorização estão o aumento do IPTU, a comodidade da infraestrutura, a melhoria no tipo de construção, e o padrão de acabamento dos imóveis nas adjacências e a construção de vias de acesso.

Entre tantos investimentos materializados na Via Verde ainda em 2011, foi anunciado mais um empreendimento, a Cidade da Justiça, que é um complexo arquitetônico com o intuito de centralizar todos os serviços da justiça em um mesmo espaço físico amplo e moderno, como nos grandes centros urbanos.

A obra está sendo construída em uma área de terra de 6 hectares, avaliada em mais de $\mathrm{R} \$ 5 \mathrm{mi}$, doada pela empresa Ipê Empreendimentos Imobiliários ao Governo do Estado e está orçada em R\$ 9.871.229,60. Em seu discurso, José Eduardo, proprietário da Ipê, fez questão de frisar que "a doação independe de qualquer retribuição ou interesse. 0 interesse, na verdade, é de contribuir com o crescimento de nossa cidade e de nosso Estado" (TJAC, 2011). Nota-se, portanto, a articulação entre esses agentes no processo de produção do espaço urbano ao juntar interesse de centralizar os órgãos públicos e direcionar o crescimento da cidade para essa área e, acima de tudo, valorizar ainda mais os lotes da Imobiliária Ipê no entorno do empreendimento.

No total, serão seis grandes blocos (Figuras 2 e 3), que, a princípio tiveram um investimento de $\mathrm{R} \$ 8$ mi provenientes de empréstimos do governo estadual com o Banco Nacional de Desenvolvimento Social (BNDES), que "ficariam por conta" do judiciário. Em um de seus pronunciamentos, o governador Sebastião Viana afirmou: "aquilo que o Governo puder fazer para colaborar, ele o fará" (TJAC, novembro de 2011).

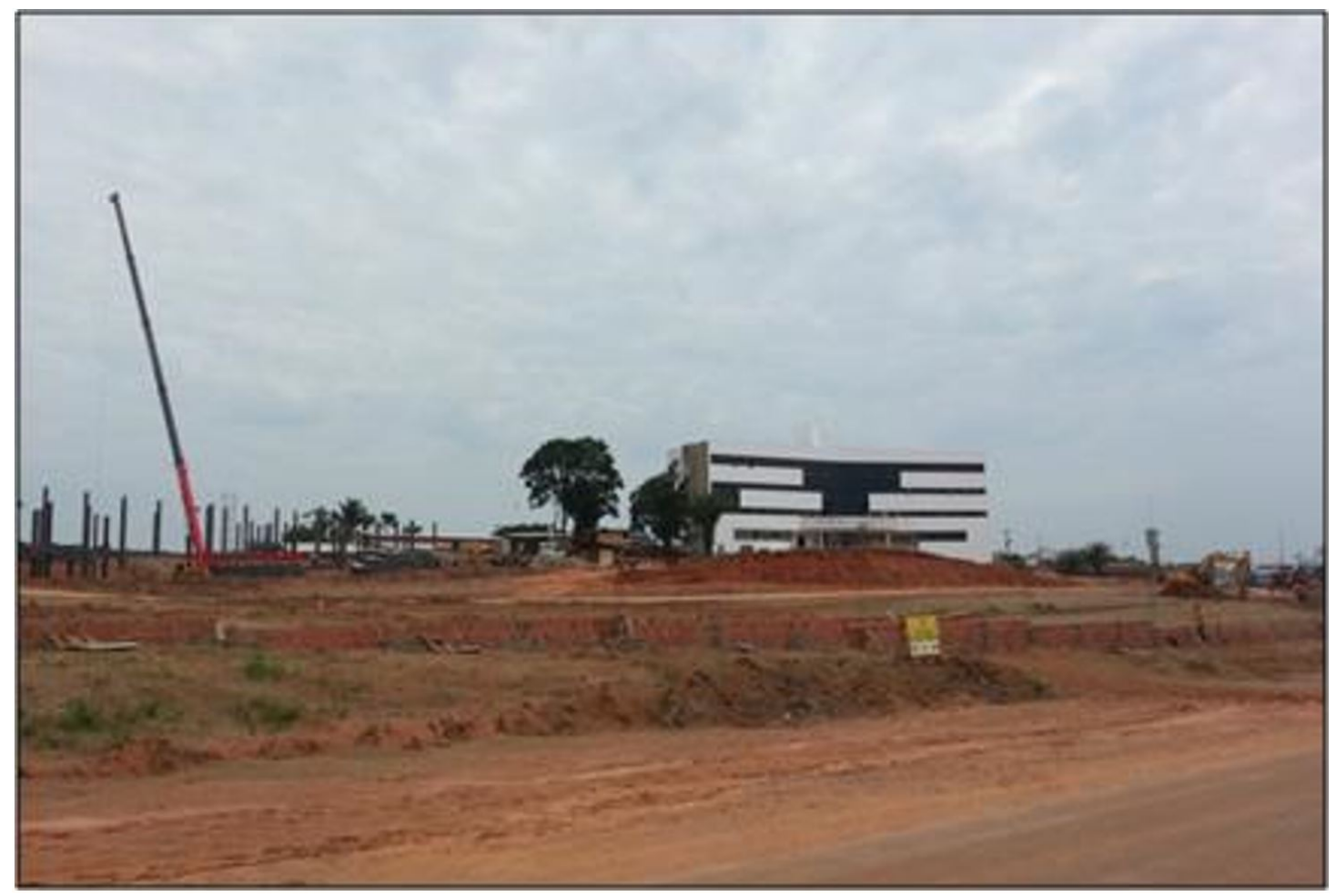

Figura 2 - Obras da Cidade da Justiça. Fonte: Janete Farias, arquivo pessoal, agosto de 2014. 


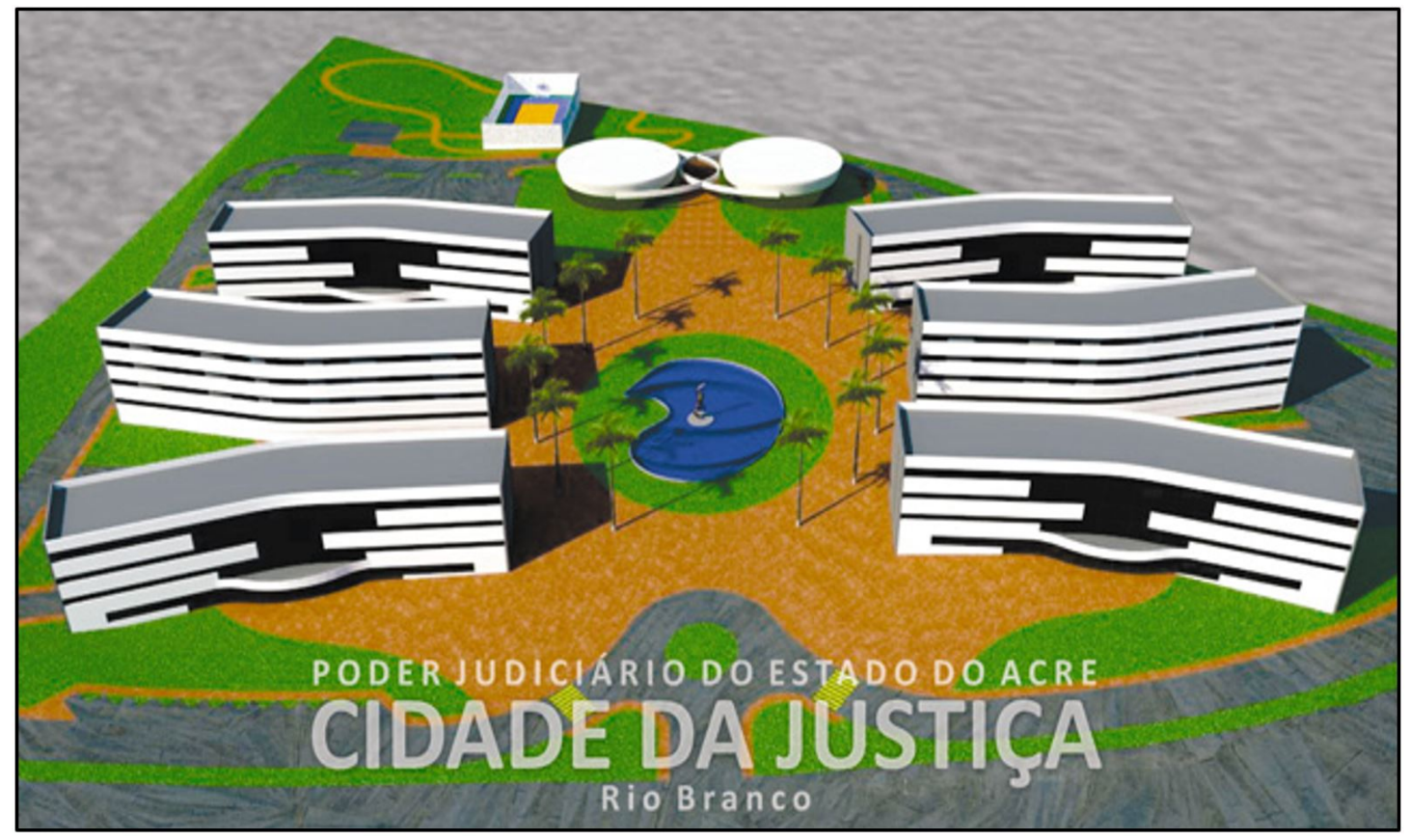

Figura 3 - Fôlder de lançamento. Fonte: TJAC, junho de 2017.

Outra parceria fundamental para a concretização do empreendimento foi com a Prefeitura de Rio Branco, que contribuiu com a urbanização do entorno do complexo arquitetônico, com investimentos de mais de $\mathrm{R} \$ 3 \mathrm{mi}$. O prefeito Marcus Alexandre ressaltou que "está tomando o cuidado de trazer materiais de qualidade para a estrutura do pavimento. Estamos fazendo alguns ajustes. Investir um pouco mais agora é economizar na manutenção no futuro" (TJAC, 2014).

A obra tem movimentado mais de 300 trabalhadores, e somente o primeiro bloco terá 150 funcionários públicos, entre servidores e magistrados. Com a conclusão dos outros cinco blocos, a movimentação de pessoas e veículos, nessa área, vai ser bastante intensa, por isso a importância de a prefeitura entrar como parceira para fazer a urbanização e facilitar o acesso da população e dos servidores. Portanto, essa tríplice parceria (Ipê, Estado e Prefeitura) está direcionando o crescimento (administrativo, econômico e social) da cidade para o entorno da Via Verde.

Há de se frisar que o poder público, ao fazer intervenções em determinadas áreas, em detrimento de outras, demonstra claramente sua articulação com os promotores imobiliários, isto é, com a classe dominante. E ainda contribui para os diferenciais de localização, por promover, no final da cadeia, uma elevação do preço do solo. Tais medidas geram um mercado imobiliário formal restrito que limita o acesso de grande parte da população aos espaços urbanos mais valorizados.

Em andamento na Via Verde está a construção do Via Towers Corporate Buildings (Figuras 4 e 5), que é um grande centro empresarial com duas torres de 16 andares. 0 empreendimento vai oferecer 10 salas comerciais por andar e também 329 vagas de garagem além do subsolo. Assim, ao observar a imagem do fôlder de lançamento, percebe-se que o empreendimento chama atenção tanto pelo seu estilo moderno quanto pela inovação arquitetônica, outrora inexistente na cidade. 


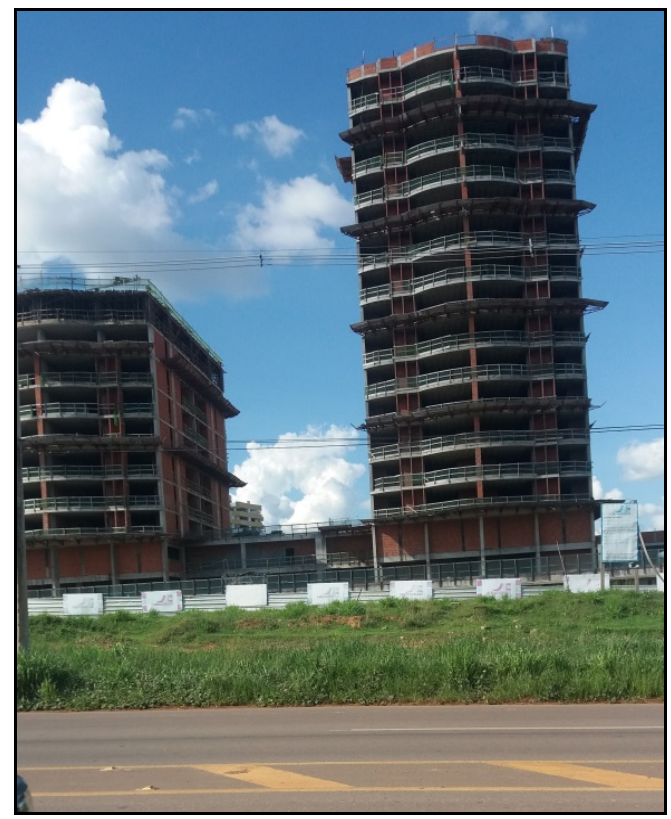

Figura 4 - Obras do Via Towers. Fonte: Janete Farias, arquivo pessoal, julho de 2017.

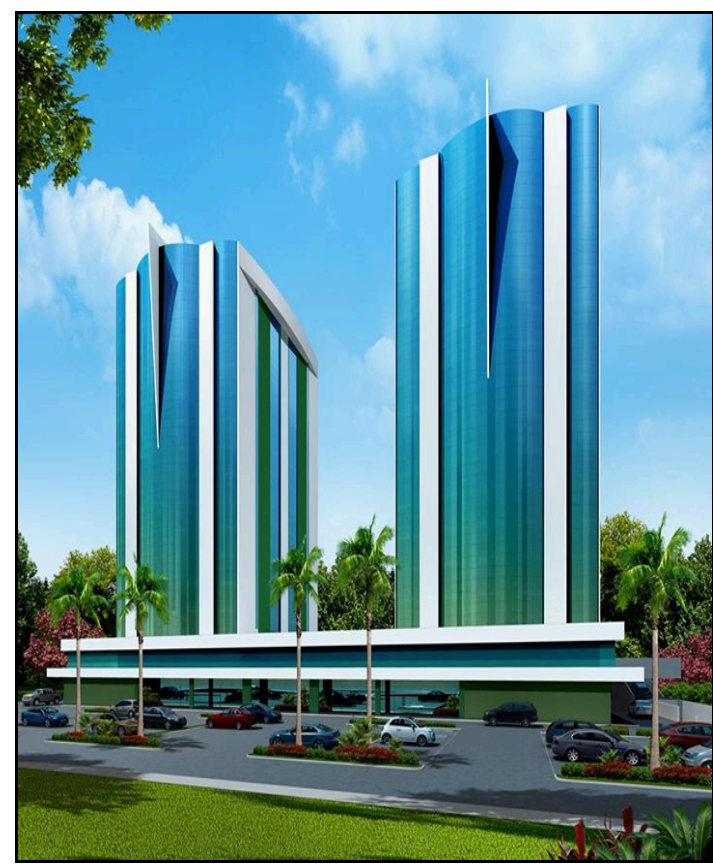

Figura 5 - Projeto do Via Towers. Fonte: Albuquerque Engenharia (2019).

A instalação de um empreendimento desse porte em Rio Branco vem, portanto, comprovar a articulação entre os agentes sociais na produção do espaço urbano na cidade. Além disso, por meio da materialização desse tipo de empreendimento, deduz-se que o crescimento econômico de parte da população de Rio Branco tem aumentado, e isso provoca a exigência de artefatos que atendam à necessidade de determinado público. Esse tipo empreendimento suscita na sociedade a "impressão" de modernidade tal como nos grandes centros urbanos.

Além desses equipamentos, existem outros já instalados na Via Verde, como os hipermercados Makro e Atacadão, o Ecoville Rio Branco (ao lado do Via Verde Shopping) e, mais recentemente, a Havan, considerada a maior de rede departamentos do Brasil. Em Rio Branco, a loja foi inaugurada no dia 5 de agosto de 2017 em frente ao Makro, ambos localizados na Via Verde (Ac 24h, 2017). 
Portanto, a Via Verde é uma nova expressão de centralidade na cidade de Rio Branco, e essa dinâmica não é apenas por ter empreendimentos novos, mas porque, no momento, nenhum outro espaço da cidade tem essa mesma dinamização entre os fluxos e os fixos, muito menos a mesma concentração de trabalhadores e consumidores se deslocando, diariamente, para o mesmo local.

\section{Valorização imobiliária na via verde e entorno}

Antes mesmo de sua inauguração, a Via Verde já apresentava indícios de especulação imobiliária e parcelamento do solo com a abertura de novos lotes e vias no seu entorno. A presença de algumas edificações institucionais desde 2005 para essa parte da cidade, como o Hospital das Clínicas (FUNDHACRE), já suscitava a convergência de grandes equipamentos urbanos para essa porção da cidade.

As grandes extensões de parcelas fundiárias vazias nas imediações do Anel Viário, associada à ação do Estado e dos promotores imobiliários, tornaram essa área e seu entorno um novo vetor de convergência do planejamento urbano racional de Rio Branco. A materialização de investimentos de serviços públicos e privados além de novas formas de habitação (condomínios e loteamentos fechados), promoveu o processo de valorização do solo e o desenvolvimento dessa parte da cidade (Tabela 1).

Tabela 1 - Valor do solo no entorno da Via Verde

\begin{tabular}{ccccc}
\hline Guia/ano & Valor do imposto (2\%) & Tamanho do terreno & Valor do terreno (R\$) & $\begin{array}{c}\text { Valor do } \mathrm{m}^{2} \\
\text { (RS) }\end{array}$ \\
\hline $316 / 2005$ & 256,58 & 612,75 & $12.829,00$ & 20,93 \\
$1529 / 2006$ & 100,00 & 300,00 & $5.000,00$ & 16,66 \\
$380 / 2007$ & $6.425,79$ & $16.877,39$ & $32.128,95$ & 19,03 \\
$1166 / 2009$ & $42.000,00$ & $25.000,00$ & 2.100 .00 & 84,00 \\
$1201 / 2011$ & $8.715,91$ & $5.947,33$ & $43.579,55$ & 73,27 \\
$2514 / 2011$ & $180.000,00$ & $40.919,12$ & $90.000,00$ & 21,99 \\
$2327 / 2013$ & $60.100,00$ & $4.939,51$ & $30.050,00$ & 608,36 \\
$1446 / 2014$ & $35.000,00$ & $15.0003,63$ & $17.500,00$ & 11,66 \\
$1826 / 2014$ & $1.538,75$ & 719,58 & $76.937,50$ & 106,92 \\
$1079 / 2014$ & $44.808,08$ & $17.081,77$ & $22.404,04$ & 131,15 \\
$1825 / 2014$ & $1.368,58$ & 704,88 & $68.429,00$ & 97,07 \\
\hline
\end{tabular}

Fonte: Prefeitura de Rio Branco. Organizado por: Janete Farias, novembro de 2017.

A Tabela 1 mostra que, na Via Verde, que foi implantada em 2006, o preço do solo nessa porção da cidade tem apresentado aumento significativo ano após ano, relacionado à materialização de investimentos públicos e privados nessa área. Ainda é possível observar que, a partir de 2009, o preço do metro quadrado cresceu em relação aos anos anteriores, o que corrobora uma maior dinamicidade econômica e imobiliária nessa área.

Nesse mesmo período, terrenos e lotes de alguns bairros próximos à BR-364 (Floresta Sul, Portal da Amazônia e outros) já demostrava, efeito da valorização, variando no percentual máximo de $\mathrm{R} \$ 30$ a $\mathrm{R} \$ 40$ mil, a depender do tamanho do terreno. Essas mudanças ocasionaram a valorização dos terrenos e lotes nos bairros próximos à Via Verde, de acordo com os classificados dos jornais "A Gazeta" e "O Rio Branco" (Quadro 1). 
Quadro 1 - Valor dos terrenos na Via Verde nos classificados

\begin{tabular}{|c|c|c|}
\hline Mês/ano & Descrição/terreno & Valor do terreno \\
\hline Jul/2005 & Portal da Amazônia & $\mathrm{R} \$ 10.000,00$ \\
\hline Ago/2005 & Jardim Europa & $\mathrm{R} \$ 7.000,00$ \\
\hline Jan/2006 & Chácara Ipê & $\mathrm{R} \$ 35.000,00$ \\
\hline Fev/2006 & Portal da Amazônia & $\mathrm{R} \$ 3.000,00$ \\
\hline $\mathrm{Jul} / 2006$ & Bairro Floresta Sul & $\mathrm{R} \$ 40.000,00$ \\
\hline Ago/2006 & Centro & $\mathrm{R} \$ 180.000,00$ \\
\hline Mai/2013 & Próximo ao Supermercado \\
\hline Nov/2014 & Portal da Amazônia I & $\mathrm{R} \$ 130.000,00$ \\
\hline Jul/2016 & Loteamento próximo ao \\
shopping & $\mathrm{R} \$ 100.000,00$ \\
\hline
\end{tabular}

Fonte: pesquisa direta, junho de 2018.

Percebe-se no Quadro 1, que os preços dos terrenos apresentam um custo menor. Essa diferença entre os preços ocorre porque esse valor do terreno é estipulado diretamente pelo proprietário que, em tese, não tem conhecimento prévio da valorização do solo na área. Já os preços estipulados pela Prefeitura (Tabela 1) apresentam um valor mais alto, por passar por avaliação de preço de mercado, tais como IPTU e ITBI, e pelos eixos de valorização, por exemplo, se possui infraestrutura, órgãos públicos e, até mesmo, proximidade com a área central.

Desse modo, essa porção da cidade continua sendo a área mais valorizada, principalmente depois da aprovação da lei que permite o parcelamento do solo para loteamentos fechados. Esse tipo de moradia de alto status está sendo parcelado também no entorno da Via Verde e dos bairros adjacentes, sendo o Ecoville Rio Branco o primeiro a ser construído no ano de 2013. Atualmente, outros três empreendimentos desse porte já foram entregues e outros três estão em processo de construção.

A materialização de investimentos na Via Verde tem, portanto, contribuído para a valorização imobiliária dessa parte da cidade. Dados do Departamento de Cadastro Técnico Multifinalitário da Prefeitura mostra a valorização imobiliária a partir do preço do metro quadrado na Via Verde e nos adjacentes (Tabela 2). A Figura 6 mostra espacialização desses bairros.

Tabela 2 - Valor do $\mathrm{m}^{2}$ nos bairros adjacentes à Via Verde em 2018

\begin{tabular}{ccc}
\hline Bairro & Área $\left(\mathbf{m}^{2}\right)$ & Valor do terreno \\
\hline Jardim Europa & $460 \mathrm{~m}^{2}$ & $\mathrm{R} \$ 15,847$ \\
Portal da Amazônia & $300 \mathrm{~m}^{2}$ & $\mathrm{R} \$ 8.031$ \\
Floresta Sul & $5.947,38 \mathrm{~m}^{2}$ & $\mathrm{R} \$ 668.663,93$ \\
Floresta Sul & $27,142 \mathrm{~m}^{2}$ & $\mathrm{R} \$ 1.804,40$ \\
Floresta Sul & $302 \mathrm{~m}^{2}$ & $\mathrm{R} \$ 40.153,92$ \\
Jardim Europa & $327,50 \mathrm{~m}^{2}$ & $\mathrm{R} \$ 23.625,85$ \\
Floresta Sul & $1.777 \mathrm{~m}^{2}$ & $\mathrm{R} \$ 97.308,52$ \\
Floresta Sul & $1.766,89 \mathrm{~m}^{2}$ & $\mathrm{R} \$ 1.161 .421,34$ \\
Floresta Sul (Ecoville) & $591 \mathrm{~m}^{2}$ & $\mathrm{R} \$ 69.938,94$ \\
Chácara lpê & $2.0247 \mathrm{~m}^{2}$ & $\mathrm{R} \$ 752.580,99$ \\
Loteamento Recanto Verde & $385,24 \mathrm{~m}^{2}$ & $\mathrm{R} \$ 50.897,90$ \\
\hline
\end{tabular}

Fonte: Prefeitura de Rio Branco. Organizado por: Janete Farias, junho de 2018. 


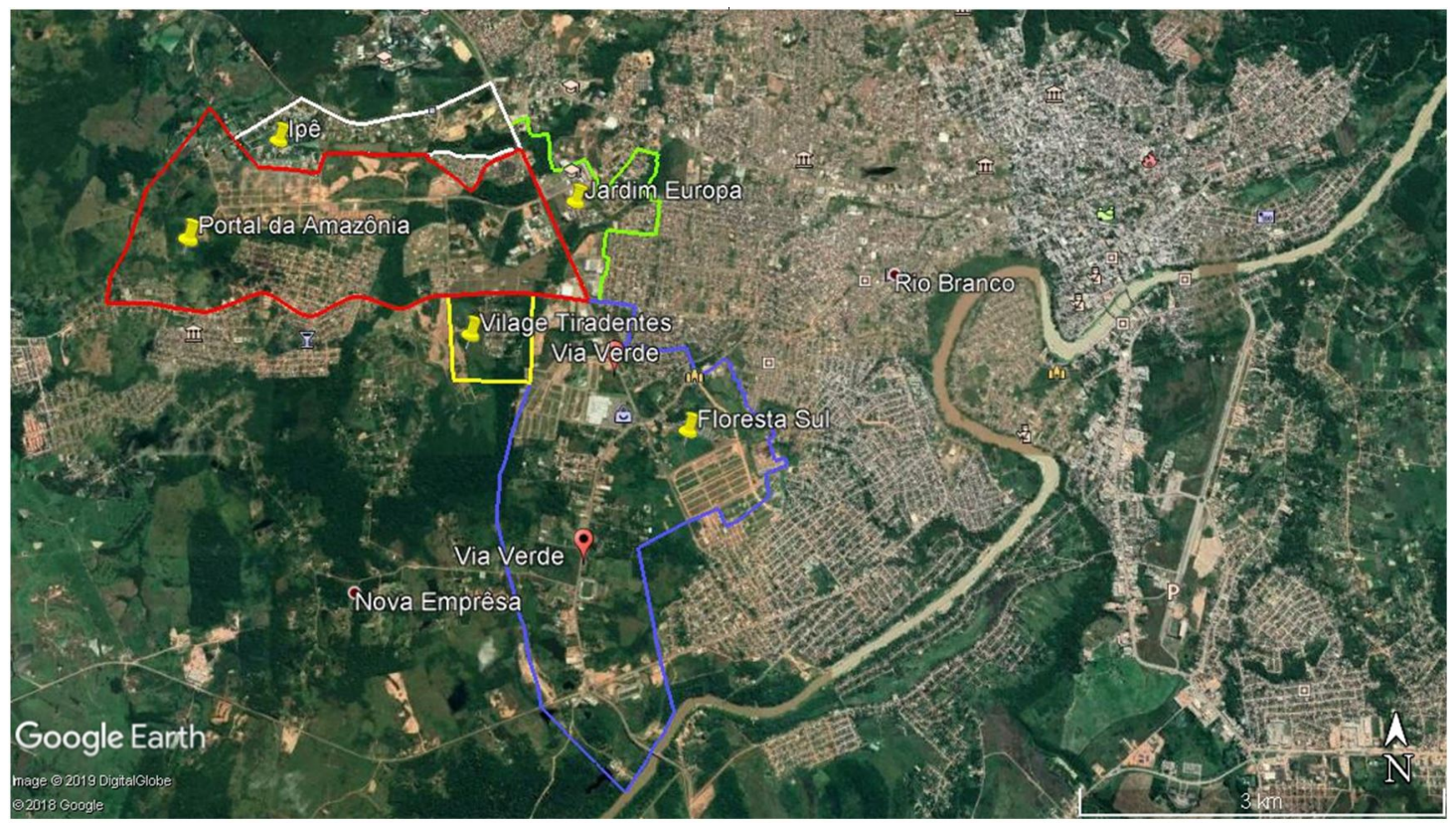

Figura 6 - Bairros adjacentes à Via Verde. Fonte: Google Earth, abril de 2019.

O valor final do terreno é definido de acordo com o tamanho e a localização em relação aos polos de valorização, que é o chamado valor venal. Na Tabela 2, é possível observar que, no bairro Floresta Sul, por exemplo, há uma oscilação de preços onde existem terrenos que vão de $R \$ 40.153,92$ até $\mathrm{R} \$ 1.161 .421,34$. Portanto, nessa área, os lotes são os que apresentam os preços mais altos da cidade.

A avaliação dos custos médios no Sistema Nacional de Pesquisa de Custos e Índices da Construção Civil (SINAPI) divulgada pelo IBGE para a região Norte e para o Estado do Acre, permitiu definir alguns valores (Figura 7). Os dados do IBGE apontam que, na região Norte, o custo médio do $\mathrm{m}^{2} \mathrm{em}$ maio (última atualização) de 2018 era de $\mathrm{R} \$ 306,00$, enquanto que no Acre, o valor ficava em torno de $\mathrm{R} \$ 330,00$, ou seja, acima da média para a região Norte.

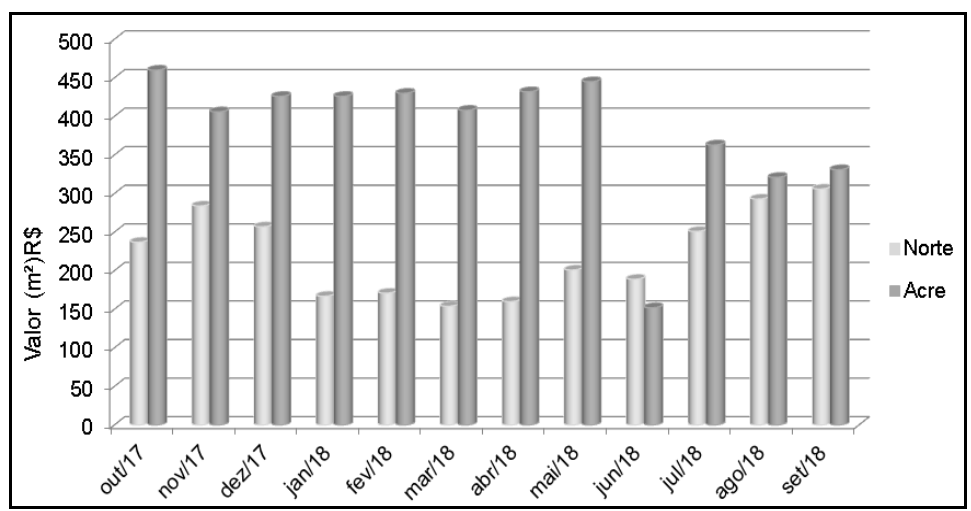

Figura 7 - Variação do valor do $m^{2}$ na região Norte e no Estado do Acre. Fonte: Instituto Brasileiro de Geografia e Estatística (IBGE, 2018).

Os dados demonstram que, em 12 meses, o valor do $\mathrm{m}^{2}$ no Acre permanece superior ao valor da região Norte. Esse dado é bastante considerável por se tratar de um Estado longínquo dos grandes centros econômicos e com o mercado imobiliário ainda em ascensão. Somente nos dois últimos trimestres de 2018 é que os percentuais entre os dois indicadores mais se aproximaram. Essas informações dão conta do que está sendo tratado, ou seja, que o preço do solo urbano no Acre é um dos mais altos do país, ficando atrás apenas dos grandes centros metropolitanos, como São Paulo e Rio de Janeiro. 
Além do tamanho e da localidade, existem outros fatores que influenciam no valor do terreno, que são os chamados pontos de valorização. Em todos os municípios, há áreas de maior valorização que podem ser lineares ou pontos específicos, e o fator determinante para o valor do $\mathrm{m}^{2}$ é a influencia exercida no entorno. Os pontos de valorização de Rio Branco foram definidos de acordo com a Lei no 1.560/2005 (Rio Branco, 2005), que trata da Planta Genérica de Valores do município, em principais e secundários.

Os centros comerciais são os polos principais e os outros polos secundários são constituídos por meio da melhoria nos serviços urbanos, por exemplo, urbanização de ruas, praças, centro histórico, entre outros. Vale destacar que desde 2005, a Planta Genérica de Valores não é atualizada segundo o crescimento da cidade e a valorização dos lotes e dos imóveis. Isso implica dizer que, nos imóveis localizados em áreas mais nobres, não está sendo cobrado o IPTU de acordo com a valorização, do lugar. Sobre essa valorização o corretor de imóveis Marivaldo Nascimento da Ipê Empreendimentos menciona:

A Via Verde, principalmente entre o Hospital das Clínicas e o Shopping, tem se valorizado bastante. Lá já existem vários empreendimentos e órgãos públicos e privados. Pode-se dizer que é um novo centro, pois é a área que mais tem crescido na cidade e tem bastante procura. A Via Verde é o centro organizado de Rio Branco, e existe um projeto do Estado de levar o resto dos órgãos administrativos para essa área (Marivaldo Nascimento da Ipê Empreendimentos, Entrevista realizada em $24 \mathrm{de}$ maio de 2017).

A Via Verde é a área que mais tem crescido, e a tendência é que ela se valorize ainda mais por causa dos novos empreendimentos que estão sendo implantados e também do indicativo de que outros órgãos do governo estão previstos para ser instalados nessa área, como a Câmera dos Vereadores. Portanto, possuir uma propriedade privada nessa localidade é, de certa forma, um bom investimento, tendo em vista os distintos interesses do poder público e do mercado imobiliário, que geram especulação e valorização do lugar.

\section{Considerações finais}

Como foi visto, o processo de descentralização está associado à junção de vários fatores, como as deseconomias de aglomeração da área central e o crescimento demográfico e espacial da cidade. Esse mesmo processo tem acontecido na cidade em Rio Branco, cidade que tem passado por várias transformações de cunho estrutural nos últimos anos.

A descentralização dos primeiros serviços públicos para essa porção da cidade não significa que já houve (re)centralização, pois as novas expressões de centralidade só se realizam quando há uma concentração e/ou dinamização significativa entre os fluxos e os fixos.

Nas falas do governador Tião Viana, do prefeito Marcos Alexandre e do empresário (um dos proprietários) da Ipê Empreendimentos, nota-se a coligação existente entre esses agentes em levar infraestrutura para a rua próxima à Cidade da Justiça (órgão público) e às terras dos empresários. Ao fazer intervenção em áreas específicas na cidade, o poder público está favorecendo determinada classe social, ou seja, os grandes capitalistas, em vez de atender ao interesse coletivo.

Na cidade, a descentralização tem sido direcionada para a Via Verde, alça viária que se tornou uma importante via de ligação e de escoamento intra-urbano e interurbano para a cidade. A instalação de equipamentos como shopping, hipermercados, Ecoville, entre outros, ano após ano, nessa parte da cidade contribuiu para a valorização do solo para a valorização dos próprios empreendimentos, uma vez que uma construção vai valorizando outra, por exemplo, a instalação do Ecoville ao lado do Via Verde Shopping, ocorrendo a chamada valorização da valorização.

As entrevistas com os corretores permitiu constatar que a materialização dos investimentos e o direcionamento dado tanto pelo Poder Público quanto pelo os proprietários privados na Via Verde aumentou os preços dos terrenos tanto ao entorno da Via Verde quanto na BR 364. 
As estratégias mercadológicas realizadas no espaço urbano pelos promotores imobiliários atuantes nas cidades médias buscam pela fluidez nos deslocamentos intra-urbanos. Essa busca faz com que os terrenos situados nas proximidades das vias de maior escoamento próximas aos modernos meios de consumo (shoppings) sejam os lotes mais valorizados na cidade. Nesse contexto, é perceptível a mercantilização do solo no entorno da Via Verde.

A materialização desses investimentos fez dessa parte da cidade a nova expressão de centralidade de Rio Branco, não apenas por ter novos empreendimentos, mas também por ter a maior concentração de investimentos, de fluxos e de trabalhadores dos setores público e privado da cidade.

\section{Referências}

Ac 24h (2017). Rio Branco. Recuperado em 21 de julho de 2017, de http://www.ac24horas.com/2017/04/20/rede-havan-deve-inaugurar-filial-em-rio-branco-e-oferece-cerca-de200-vagas-de-emprego/

A Gazeta do Acre. (2011). Rio Branco. Recuperado em 5 de junho de 2017, de http://agazetadoacre.com/noticias/tudo-pronto-para-a-inauguracao-do-via-verde-shopping-na-capital

Albuquerque Engenharia. (2019). Rio Branco: Albuquerque Engenharia. Recuperado em 02 de maio de 2019, de http://www.albuquerqueengenharia.com.br/

Bessa, K. C. F. O., Silva, E. A. M., \& Soares, B. R. (1996). “Vazios” urbanos e especulação imobiliária em UberlândiaMG. Sociedade \& Natureza, 3(16), 160-175.

Corrêa, R. L. (1989). O espaço urbano. São Paulo: Ática.

Corrêa, R. L. (2012). Sobre agentes sociais, escala e produção do espaço: um texto para discussão. In A. F. A. Carlos, M. L. Souza \& M. E. B. Sposito (Orgs.), A produção do espaço urbano: agentes e processos, escalas e desafíos (1a ed., 1a reimpressão). São Paulo: Contexto.

Correio 24horas. (2012). Bahia. Recuperado em 12 de junho de 2017, de

http://www.correio24horas.com.br/detalhe/noticia/valorizacao-de-imoveis-vizinhos-a-shopping-chega-a-90/

Google Earth. (2019). Recuperado em 02 de abril de 2019, de

https://www.google.com.br/earth/download/gep/agree.html

Instituto Brasileiro de Geografia e Estatística - IBGE. (2018). Cidades. Censo demográfico 2010. Rio de Janeiro: IBGE. Recuperado em 09 de outubro de 2018, de https://cidades.ibge.gov.br/brasil/ac/panorama.

Montessoro, C. C. L. (1999). Presidente Prudente: a instalação dos shoppings centers e a (re)estruturação da cidade. Presidente Prudente: UNESP.

Oliveira, G. A. Jr (2010). Espacialidades e temporalidades: expressões de centralidade em cidade médias. Mercator, 9(19), 97-100.

Ribeiro, V. Fo (2004). A área central e sua dinâmica: uma discussão. Sociedade \& Natureza, 16(31), 155-167.

Rio Branco. Câmara Municipal. (2005, 8 de dezembro). Lei n. 1.560, de 08 de dezembro de 2005. Planta Genérica de Valores do Município de Rio Branco. Rio Branco: Recuperado em 02 de abril de 2019, de http://portalcgm.riobranco.ac.gov.br/lai/orientacoes/planta-generica-de-valores-do-municipio-de-rio-branco/

Silva, A. L. (2013). Breve discussão sobre o conceito de cidade média. Geoingá: Revista do Programa de PósGraduação em Geografia, 5(1), 58-76.

Silva, W. R. (2003). A formação do centro principal de Londrina e o estudo da centralidade urbana. Geografia, 12(2), 21-44. 
Silva, W. R. (2008). A redefinição da centralidade em cidades médias. Londrina e Maringá no contexto da reestruturação urbana e regional. In Anais do X colóquio internacional de geocrítica. Barcelona: Universidad de Barcelona. Recuperado em 20 de dezembro de 2018, de http://www.ub.edu/geocrit/-xcol/37.htm

Sposito, M. E. B. (2001). Novas formas comerciais e a redefinição da centralidade intra-urbana. In M. E. B. Sposito, Textos e contextos para a leitura geográfica de uma cidade média. Presidente Prudente: FCT/UNESP.

Sposito, M. E. B. (2006). Loteamentos fechados em cidades médias paulistas - Brasil. In Sposito, E. S.; Sposito, M. E. B. \& Sorbazo, O. (Orgs.). Cidades médias: produção do espaço urbano e regional. São Paulo: Expressão Popular.

Tribunal de Justiça do Acre - TJAC. (2011). Rio Branco: Recuperado em junho de 2017, de http://www.tjac.jus.br/noticias/noticia.jsp?texto=13254.

Tribunal de Justiça do Acre - TJAC. (2014). Cidade da Justiça: Tribunal de Justiça e Prefeitura de Rio Branco discutem urbanização do empreendimento. Rio Branco: TJAC. Recuperado em 02 abril de 2019, de https://www.tjac.jus.br/noticias/cidade-da-justica-tribunal-de-justica-e-prefeitura-de-rio-branco-discutemurbanizacao-do-empreendimento/

\section{Editor: Fábio Duarte}

Recebido: Jul. 09, 2018

Aprovado: Dec. 11, 2018 